\title{
Refinery waste: the spent hydroprocessing catalyst and its recycling options
}

\author{
M. Marafi \& M. S. Rana \\ Kuwait Institute for Scientific Research, Kuwait
}

\begin{abstract}
An industrial waste spent residue hydroprocessing catalyst, contains high levels of metals and carbon, which decreases catalytic activity and forces the refiner to replace the catalyst. The catalyst was unloaded from a KNPC refinery atmospheric residue desulfurization unit. Recycling of spent catalyst waste is at the leading edge of environmentally sound technology and sets the standards for handling the solid waste in the refinery as it is considered hazardous. Hence a concept for a recycling approach to minimize industrial spent catalyst waste has been applied for the recovery of metals $(\mathrm{Ni}, \mathrm{V}, \mathrm{Mo})$ as a first step while supporting $\left[\mathrm{Al}(\mathrm{OH})_{3}\right]$ in a subsequent process. The recycling of a spent catalyst involves various steps such as de-oiling, drying, grinding, sieving, and decoking. In the subsequent steps, the de-coked spent catalysts were treated with acid-base reaction media to separate the various components of the spent catalyst. The metal recovery as a function of leaching agents has been investigated by using hydrometallurgical processes. A brief account has also been reported for conventional processes and recent approaches employed by using pyro-metallurgical and hydrometallurgical routes. Considering various routes of metal extractions, the EDTA containing chelation process has shown its potential in high value metal extraction of up to $99 \%$ recovery. The recovered metals and support have enabled industrial application for use as alternative raw materials for catalyst preparation.
\end{abstract}

Keywords: spent catalyst, hazardous waste, waste utilization, metal recovery.

\section{Introduction}

The worldwide petroleum feedstock scenario is changing toward heavier crudes, which is expected to play a crucial role in processing these crudes with more difficulties and affecting existing refining systems. The heavy oil and its residue 
contains more metals $(\mathrm{Ni}+\mathrm{V})$, sulfur, nitrogen and has low API gravity, which has a negative effect on various processes and decreases catalytic activity with timeon-stream (TOS). Hence, the blocking of catalyst active sites by certain elements or compounds on the surface are the main causes of catalyst deactivation $[1,2]$. After deactivation, the catalysts need to unload, which is usually know as refinery spent catalyst waste. Refineries need to treat their waste streams according to the Environmental Protection Agency (EPA) in order to disseminate hazardous waste. Hence, disposal of a spent catalyst is a common problem as it falls under the category of hazardous industrial waste [2]. As a result, worldwide catalyst consumption has increased considerably and is expected to increase further $[2,3]$. A refinery mainly contains four types of catalysts such as FCC, hydrotreating, hydrocracking and alkylation. The catalyst market and factors affecting the price and consumption are based on demand and fuel specifications in the specified region. Hydrotreating catalysts, which account for more than half of the hydroprocessing market, are mainly manufactured by Criterion, Albemarle, Haldor Topsøe, ART, Axens and UOP [3]. Usually recent high active hydrotreating/hydrocracking catalysts are quite expensive and their deactivation is faster than before mainly due to the heavier feedstock. Thus, refiners are now focusing seriously on regenerability of spent catalysts.

An expected catalyst market growth rate of $4.24 \%$ between 2014 and 2019 has been reported $[3,4]$, and is projected to generate $\$ 6,708$ million by 2019 . In recent years, hydrotreating catalysts have dominated the refinery catalysts market by type, which is projected to reach $\$ 2,213$ million by 2019 . The expected high growth rates are mainly due to the high market demand in Asia-Pacific while in Europe and North America it is fully developed and is expected to perform below average.

Considering the above said market and catalyst consumption, the region will be generating spent catalysts accordingly. Hence, the global energy trend and economic development forces refiners to increase the product profitability along with severe process conditions as well as with the expense of a lower catalyst life. Therefore, catalyst companies are merging and meeting the demand of product quality as catalyst availability. Usually, complex refineries at about 8-10 petroleum refining processes generate waste catalysts. However, the most important are listed in Figure 1.

The spent catalysts from these processes are classified by EPA as refining waste or hazardous waste $[5,6]$. Although, the rule can vary depending on individual circumstances, refiners are obliged to apply for their specific operations. Residue hydroprocessing or direct upgrading processes produce most of the large amounts of spent catalysts, which contain metals like Mo, Co, Ni, V, $\mathrm{Fe}$ and $\mathrm{Al}$ in the form of metal oxides and sulfides [1]. using heavier feedstock that contains a broad range of boiling hydrocarbon fraction and carries various types of contaminants such as metals and asphaltene [7, 8]. Hence, catalyst deactivation is an inevitable phenomenon that involves both chemical and physical changes in the catalyst nature.

In the complex petroleum refinery large amounts of waste spent catalysts are being generated, which have a high content of metals and valuable alumina 


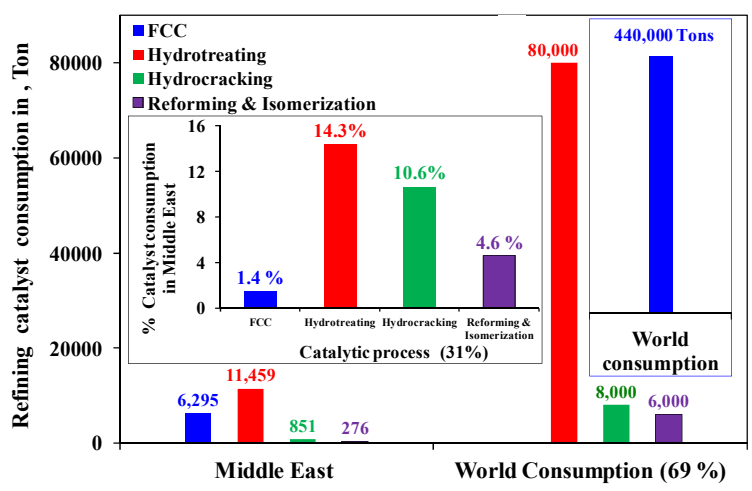

Figure 1: Worldwide catalyst consumption in petroleum refining.

support. Therefore, refineries look forward to recycling options, where recovered metals or alumina either can be re-used for catalyst preparation or can be used in the metal industries. For a small country like Kuwait, disposing in landfills is a huge concern while a considerable amount of spent catalysts is being produced (figure 1). The Middle East has a large consumption of refinery catalysts, particularly hydroprocessing. In Kuwait, catalytic hydrotreating processes are used extensively in Kuwait National Petroleum Company (KNPC); three refineries which generate large quantities (6000-7000 tons) of spent catalysts as solid waste every year. The amount of spent catalyst waste is expected to increase further in the coming years because of a fourth new refinery (Al-Zour refinery) and increasing diesel hydrotreating capacity to meet the growing demand for clean fuel with ultra-low sulfur diesel.

Therefore, recycling methodologies and eco-friendly cost-effective ways have been investigated for atmospheric residue desulfurization (ARDS) refinery spent catalysts in order to minimize spent catalyst waste and to protect the environment. Moreover, it is worth finding a proper way of treatment using pyro-metallurgical together with hydrometallurgical techniques that have been applied and investigated in order to recover valuable metal and support from the spent hydroprocessing catalyst.

\section{Experimental}

An ARDS spent catalyst containing valuable metals like Ni, Co, V, Mo and Al, was obtained from the KNPC. The deposited carbon (coke) and metals on the spent catalyst were determined using thermogravimetry analysis (TGA) and scanning electron microscopy (SEM/EDX), respectively. The composition of the spent catalyst also conformed with inductively coupled plasma (ICP) indicating that a considerable amount of foreign species were deposited (as shown in Table 1). Refinery, ARDS hydroprocessing catalysts have been recovered from a guard reactor (R1), HDM/HDS catalyst (R2) and HDS catalyst (R3) and the final 
Table 1: $\quad$ Spent catalysts unloaded from the (ARDS) system.

\begin{tabular}{|c|l|l|l|l|c|}
\hline \multirow{2}{*}{ Properties } & \multicolumn{5}{|c|}{ Spent catalyst from different reactors } \\
\cline { 2 - 6 } & R1 & $\mathbf{R 2}$ & $\mathbf{R 3}$ & $\mathbf{R 4}$ & Average \\
\hline Surface area (SSA), $\mathrm{m}^{2} / \mathrm{g}$ & 100 & 120 & 180 & 200 & - \\
\hline Pore volume (TPV), $\mathrm{ml} / \mathrm{g}$ & 1.1 & 0.92 & 0.85 & 0.66 & - \\
\hline APD, nm & 28 & 25 & 25 & 12 & - \\
\hline Composition, wt. \% & & & & & \\
\hline Mo & 1.73 & 1.62 & 6.68 & 9.31 & 5.9 \\
\hline $\mathrm{Ni}$ & 3.99 & 5.49 & 5.6 & 4.9 & 5.3 \\
\hline $\mathrm{V}$ & 19.67 & 26.1 & 10.49 & 4.12 & 13.6 \\
\hline $\mathrm{Al}$ & 28.56 & 21.8 & 31.75 & 36.6 & 30.1 \\
\hline Carbon, wt \% & 25 & 28 & 35 & 45 & 36.0 \\
\hline
\end{tabular}

hydrocracking (R4) catalyst. All the spent catalysts were mixed in a proportion, which was used for metal recovery $[10,11]$.

The catalysts were in the form of cylindrical extrudates of approximate diameter of about $0.4 \mathrm{~mm}$ and length $5-6 \mathrm{~mm}$, which were deoiled, decoked, crushed, and ground to fine powder (size $<500 \mu \mathrm{m}$ ) using standard equipment and procedures $[10,12]$. The powdered deoiled spent catalyst was then decoked by combustion of coke under controlled temperature conditions in the range of 300 to $600^{\circ} \mathrm{C}$ for $8 \mathrm{~h}$ in an oxygen atmosphere (i.e., $5 \% \mathrm{O}_{2}$ in $\mathrm{N}_{2}$ ). Figure 2 shows a pretreatment process, which is common for all the leaching processes.

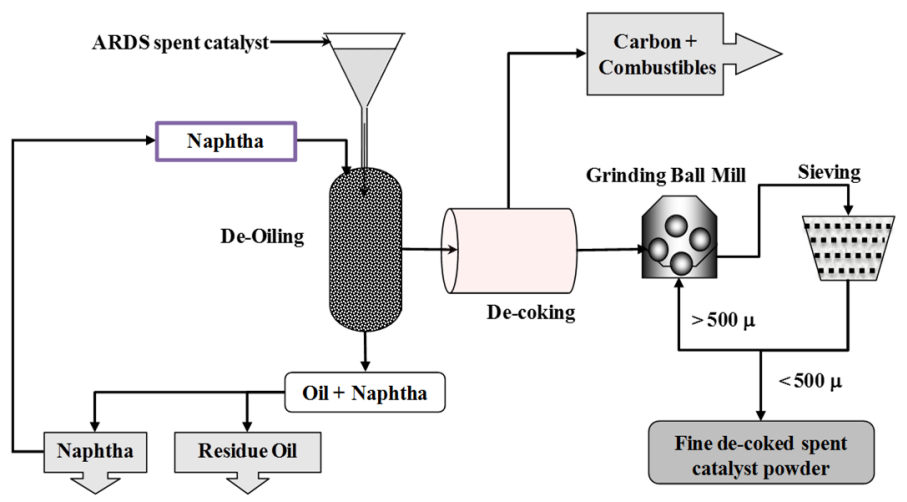

Figure 2: Spent catalyst de-oil, de-coke and grinding before metal recovery.

\section{Results and discussion}

\subsection{Characterization of spent catalysts}

Generally, the life of an ARDS hydroprocessing catalyst is about 10 to 15 months. However, global refinery spent catalyst production has increased since heavy 
crude oil started processing, which deactivates catalysts faster and shows higher metal and carbon deposition [1]. In the present study, the total carbon deposited on the catalyst was measured using TGA, which is at about $43 \mathrm{wt} \%$. TGA/DTA shows two obvious weight losses for all the spent catalysts in the temperature range of $50^{\circ} \mathrm{C}$ to $800^{\circ} \mathrm{C}$ (as shown in Figure 3).

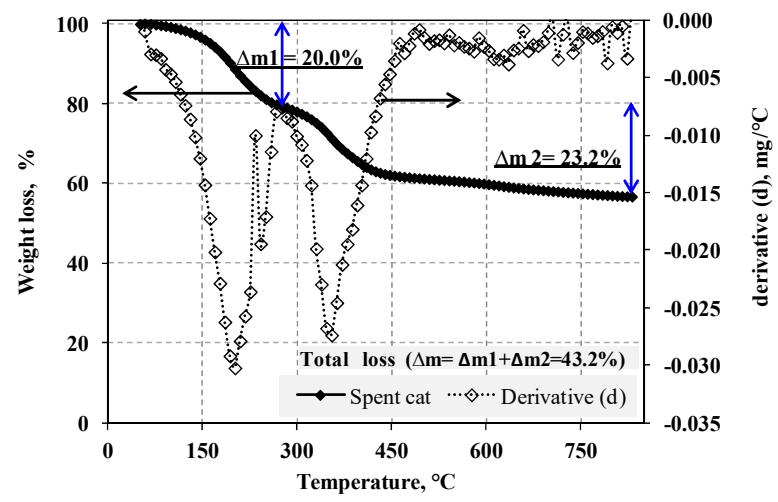

Figure 3: TGA profiles of the spent catalysts recovered from the ARDS process.

TGA results indicated that the first weight loss in the range of $50^{\circ} \mathrm{C}$ to $260^{\circ} \mathrm{C}$ is attributed to soft coke desorption, and the second weight loss in the range of $300^{\circ} \mathrm{C}$ to $450^{\circ} \mathrm{C}$, accompanied by exothermic effect, is assigned to medium coke removal. The amounts of coke deposit calculated from TG curves at different stages are shown in figure 3, i.e., 43.2 weight $\%$ of the fresh catalyst. On the other hand, SEM-EDAX results confirmed that carbon, V, Ni, P, and Mo (sulfur) are deposited on the surface of the catalyst, which are featured by their $\mathrm{K} \alpha \mathrm{X}$-ray emission lines (keV) (as shown in Figure 4).

Displayed semi-quantitative results from different elements along the line analysis are shown in the figure 4 inset. The $\mathrm{V}$ metal is usually deposited on the surface while $\mathrm{Ni}$ is distributed more homogeneously indicating the diffusion of $\mathrm{Ni}$

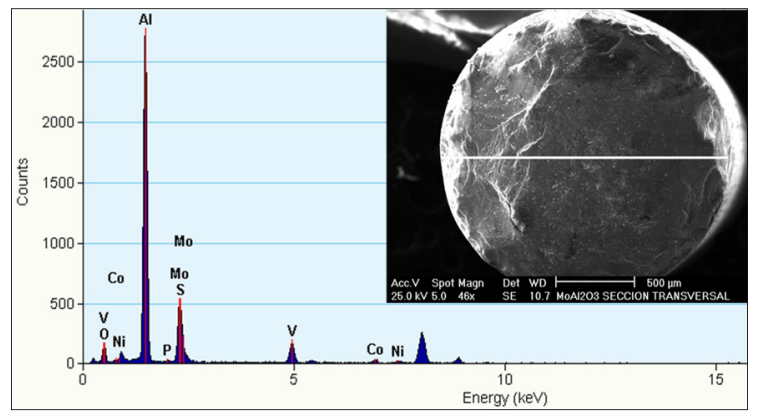

Figure 4: Radial analysis of deposited metals using SEM-EDS analysis. 
deeper on the catalytic pore or sites $[1,13]$. Since Ni and V complex molecules are present in a porphyrin-type coordination, the distribution of metal deposition is more related to the possible existing form of the metals where $\mathrm{V}$ metal in vanadium porphyrins exist as ( $\mathrm{VO}) 2+$ in which the $\mathrm{V}$ atom easily can deposit on the surface of the catalyst/support and get removed faster, which leads to surface deposition of vanadium sulfide near the pore mouth.

\subsection{Recycling options for spent hydroprocessing catalysts}

A spent catalyst, if it contains only $\mathrm{Al}, \mathrm{Si}$, and $\mathrm{Fe}$, can be disposed of without any special precautions or can be used in construction materials. However, in hydroprocessing, spent catalysts mainly contain $\mathrm{Ni}$ and $\mathrm{V}$ accumulated during their use, then for removal of these elements the below legislative limits is necessary $[14,15]$. Hence, before disposal, spent catalysts containing various contaminants need to be encapsulated to avoid their release into water and the environment. There are methods that reduce catalyst waste by using post treatment methods or spent catalyst management such as regeneration, rejuvenation, reuse either in fresh catalyst preparation or reusing in less severe hydrotreating units by cascading before final disposal.

Usually, two major methods have been applied for recovery of metals or separate various components of the spent catalyst, namely, pyrometallurgy and hydrometallurgy. Pyrometallurgical processes require high heating in which the waste catalyst is treated at high temperatures to recover valuable metals and decompose hydrocarbon. These treatments lead to the production of hazardous gases that must be removed from the air with flue gas cleaning systems. This process is considered energy intensive, high-cost and requires high-grade feeds. Hydrometallurgy; it is also called leaching process, involves the selective dissolution of metals from their waste. It involves the use of aqueous chemicals (acid and base) and leaching and/or metal separation processes are carried out at much lower temperatures.

\subsubsection{Regeneration, rejuvenation and the reuse of spent catalysts}

Regeneration of spent catalysts is a longstanding common process. The process contains pyarolytic oxidation of carbon and sulfur from the catalyst. Regeneration is generally utilized when the metal contaminants are low or negligible on the catalyst. The process holds only a sophisticated temperature (heating rates) and gases (air, nitrogen or oxygen) flow control systems used for moving as well as fixed bed processes in order to burn carbon and sulfur in the presence of oxygen. The controlled temperature is to avoid changes in catalyst properties during regeneration or heating, such as hot spots, active metal sintering, collapsing pores, which prevent surface area reduction and sintering, minimize breakage and attrition. During the regeneration, some of the active metal may react with support particularly promoters $(\mathrm{Ni}$ or $\mathrm{Co}$ ) may react with alumina and form spinel $\left(\mathrm{CoAl}_{2} \mathrm{O}_{4}\right.$ or $\left.\mathrm{NiAl}_{2} \mathrm{O}_{4}\right)$, which explains why the catalytic activity of the fresh catalysts were not fully recovered after the regeneration of the spent catalyst. Although a regenerated catalyst can either be used in the same process or in other applications requiring less degree of catalytic activity. Therefore, any damage by 
carbon deposition can be partially repaired via coke burning, which is also known as rejuvenation [16].

Regeneration either can be done within the same plant where it is used (in-situ) or can be off-site, depending on the use after the regeneration. On the other hand, where the metal contaminants are high on spent catalyst regeneration and rejuvenation is not a practical process because catalysts are susceptible to irreversible deactivation caused by adsorption of metal impurities, such as $\mathrm{V}$ and Ni. Not only is there a gradual build-up of these impurities in a hydrotreating catalyst but also eventually plugging the pores and generating diffusion limitations. Therefore, a typical first step is to identify and analyse the composition of the spent catalyst in order to find out its regenerability.

A spent catalyst also can be fully re-used in cement manufacturing, building material (porous blocks), asphalt paving, and construction. Therefore, the cement industry is considered to be one of the key sectors where large amounts of spent solid waste catalyst can be effectively used either as an additive or as raw materials in the manufacturing mixture of tiles. Recently, thermal plasma technology has been applied in various industrial applications of waste treatment $[17,18]$, which cracks or reforms all organic substance and vitrifies inorganic matter into rocks.

However, major production of spent catalysts in residue treatment are mainly from ARDS and residue fluid catalytic cracking (RFCC). Such catalysts are also high in metals, sulfur, and coke along with most of the pores being either plugged or partially reduced. Usually, due to the presence of zeolite in the support RFCC the catalyst has acidic composition and has a higher rate of deactivation. The use of spent catalysts for the preparation of an active HDM catalyst has been reported in previous studies [19]. Such type of catalyst, even without decoking, can be used as the presence of carbon in the support is also known to have a beneficial effect on the hydroprocessing catalyst [20]. In addition, carbon will be burnt during the support calcinations that leads to enhanced larger pores in the catalyst [21]. A flow diagram for spent catalyst re-use with boehmite mixtures was tested for physical, chemical and mechanical properties as well as durability and integrity [19]. The concentration of heavy metals in the above applications of reusing ARDS/RFCC spent catalyst leads to a beneficial effect as a fresh catalyst.

\subsubsection{Hydrometallurgical treatment options for metal recovery}

Hydrometallurgy treatment, also known as leaching method for recovery of valuable metals from a waste spent catalyst, has more flexibility during the upscaling and has various options available for the purification and selective recovery by using the following specific chemical treatments.

3.2.2.1 Soda roasting and metal leaching The soda roasting leaching process selectively used to extract $\mathrm{V}$ and $\mathrm{Mo}$, while $\mathrm{Ni}(\mathrm{Co})$ will remain unreactive as a solid in alumina, which can be further digested in $\mathrm{NaOH}$ at high pressure and dissolve (as shown in Figure 5). Using a roasting temperature at $550^{\circ} \mathrm{C}$, the yield of recovery for Mo and $\mathrm{V}$ with $\mathrm{NaOH}$ was more than $95 \%$, while with $\mathrm{Na}_{2} \mathrm{CO}_{3}$ extraction was more selective to the Mo and $\mathrm{V}$ removal without reacting to the $\mathrm{Ni}$ and $\mathrm{Al}[22]$. 


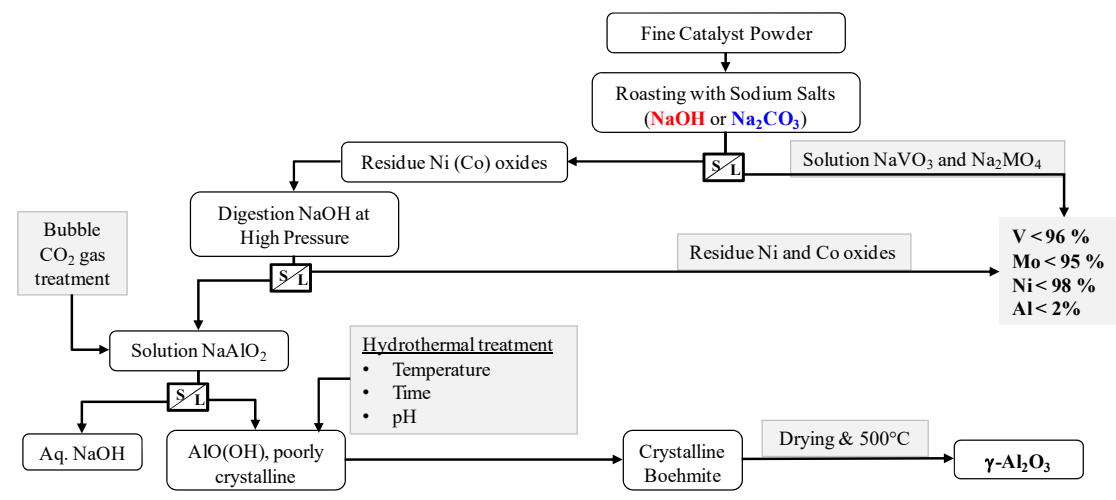

Figure 5: The soda roasting process for metal and high purity alumina recovery.

However, by increasing the sodium carbonate roasting temperature to $700^{\circ} \mathrm{C}$ the Mo and V recovery reached up to $99 \%$, which made an easy separation for Mo and $\mathrm{V}$. Since $\mathrm{Ni}$ and $\mathrm{Al}$ do not react with $\mathrm{Na}_{2} \mathrm{CO}_{3}$, it remains as a residue. A comparison between two roasting agents has concluded that the optimum conditions for maximum recovery of $\mathrm{Mo}$ and $\mathrm{V}$ metals content were achieved at a reaction temperature of $700^{\circ} \mathrm{C}, 120$ min leaching time with $25 \%$ of $\mathrm{Na}_{2} \mathrm{CO}_{3}$ while using $\mathrm{NaOH}$ the optimum conditions are $480^{\circ} \mathrm{C}, 60$ min leaching time and $50 \%$ concentration. The soda roasting process has an advantage over other processes for the recovery of high quality (purity) boehmite, which properties can be further modified with the hydrothermal treatment based on the type of alumina requirement for further use. Therefore, the roasting technique met the rations of integrated recycling and it has advantages, such as single step operation, high recovery yield of water soluble metals particularly for Mo and V.

3.2.2.2 Basic leaching Ammonium salts based solutions are weakly basic and have a slightly acidic character. Therefore, they can be effectively used as exhilarating leaching agents for surface metal extraction [23]. The leaching was performed by using an aqueous solution of ammonia and ammonium salts with the previously ground spent catalyst (Figure 6). Different metal extraction have been reported as a function of the leaching agent. The use of oxidizing $\left(\mathrm{H}_{2} \mathrm{O}_{2}\right)$ agent also was tested, which is environmentally safe and does not produce reaction products except water. In the case of ammonium per-sulfate (APS), it has about $7 \mathrm{wt} \%$ active oxygen that acts as an oxidizing agent and improves $\mathrm{Ni}$ and $\mathrm{Al}$ extraction in comparison with other leaching agents, namely, $\mathrm{NH}_{4} \mathrm{OH}$ and $\left(\mathrm{NH}_{4}\right)_{2} \mathrm{CO}_{3}$. The different behavior using APS could be due to its strong oxidizing nature, which promotes better dissolution of metals. However, APS also forms oxygen free radicals in an aqueous solution and that adds some advantages for metal recovery but only for $\mathrm{V}, \mathrm{Ni}$ and $\mathrm{Al}$. This may be explained by the fact that APS is an acidic salt which limits Mo extraction in acidic medium. Thus, ammonia leaching reactions effectively take place at mild basic conditions in the presence 
of an oxidative ambiance. Hence, the use of ammoniacal solutions in the presence of $\mathrm{H}_{2} \mathrm{O}_{2}$ (oxidative or bleaching) may reduce the number of separation processes, and this may improve the economy of the process.

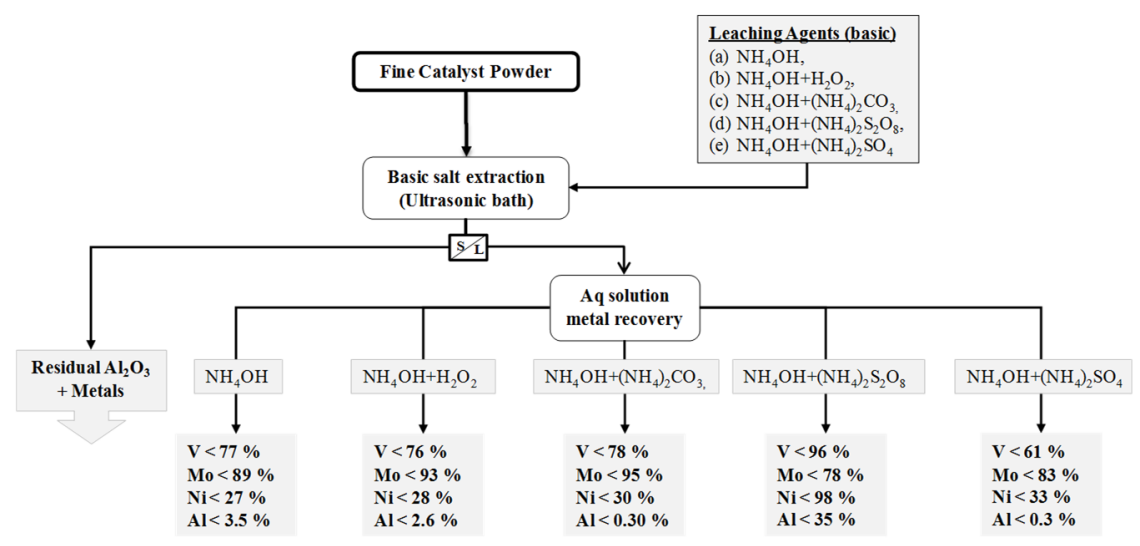

Figure 6: Flow scheme for basic leaching of spent hydroprocessing catalyst.

3.2.2.3 Acidic leaching Acidic leaching of previously ground and de-coked spent catalyst was performed in multiple steps as a function of leaching agents. It was possible to recover almost all metals (Mo, V, Ni and $\mathrm{Co}$ ) simultaneously with leaching yields of about 95\% (as shown in Figure 7).

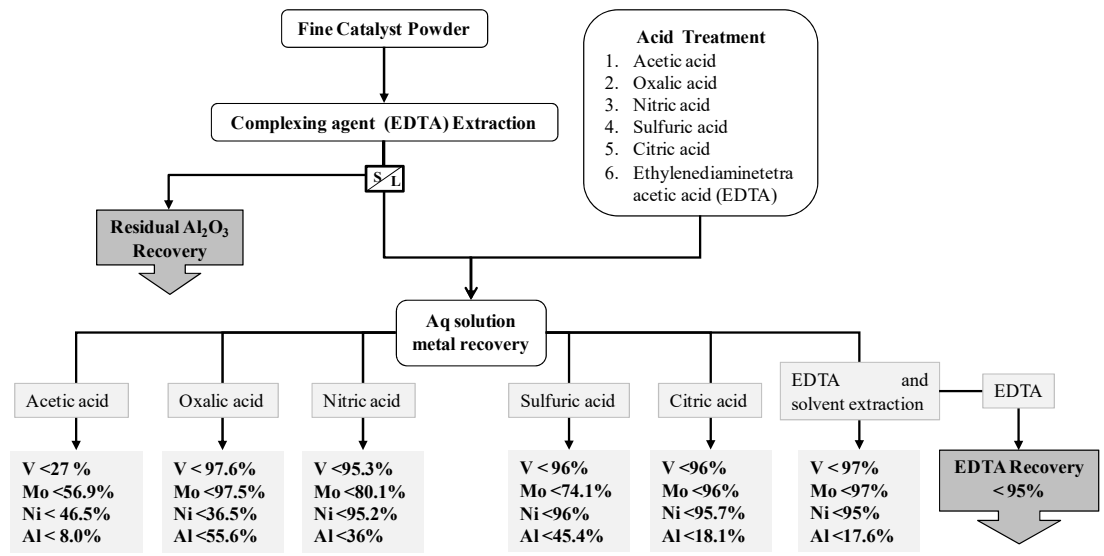

Figure 7: Flow scheme of acidic leaching of spent hydroprocessing catalyst.

The present study successfully showed pure and quantitative recovery of solvents (Cyanex 272) and costly chemicals like EDTA using different stripping steps. However, detailed discussion with deep understanding of the extraction mechanism need to be considered as future work before it can be scaled up from 
lab level to bench scale. Conventional acid leaching and organic chelation routes also have been compared for the metal recovery and purity, which is significantly high for the chelation technique than for conventional acid leaching [24].

In the acid leaching studies, the efficiencies of organic acids such as citric acid, oxalic acid and ethylenediaminetetraacetic acid (EDTA) are compared with those of inorganic acids, e.g. sulfuric acid $\left(\mathrm{H}_{2} \mathrm{SO}_{4}\right)$ and nitric acid $\left(\mathrm{HNO}_{3}\right)$. About $97 \mathrm{wt} \%$ extraction of Mo and $\mathrm{V}$ was achieved with both oxalic acid and EDTA, whereas, with citric acid, the recovery was around $92 \%$. The effectiveness (Mo and $\mathrm{V}$ extraction) of the five acids used in this study can be ranked in the following order where oxalic acid was highly effective for Mo and V extraction. Although it showed very poor activity for Ni extraction, which follows the order EDTA > Citric acid $=\mathrm{H}_{2} \mathrm{SO}_{4}>\mathrm{HNO}_{3}>\mathrm{CH}_{3} \mathrm{COOH}>$ Oxalic acid. In aluminum extraction, both organic and inorganic acids showed poor activity. Apart from the high metal recovery efficiency, the use of $\mathrm{HNO}_{3}, \mathrm{H}_{2} \mathrm{SO}_{4}, \mathrm{C}_{2} \mathrm{H}_{4} \mathrm{O}_{2}$ or $\mathrm{C}_{6} \mathrm{H}_{8} \mathrm{O}_{7}$ for metal leaching that has several disadvantages such as chemical cost, and consequences of hazardous chemicals are unavoidable.

Based on the above, the possibility of recycling of total refinery spent catalyst (TSC) was investigated using various steps for metal leaching and the alumina support recovery as bulk solid in the form of boehmite. An optimum leaching efficiency with different leaching methods and their conditions were achieved in order to obtain the maximum recovery of Mo, Ni and V metals. An overall refining catalyst system (cradle-to-grave or creation to disposal) cycle involves a number of key steps (Figure 8) such as catalyst synthesis, reactor loading, activity test run, and unloading, off-site regeneration, reuse, reclamation, and disposal. The full recycling process was shown by a number of steps such as: (A) support extrusion; (B) CoMo/NiMo fresh catalyst synthesis; (C) bench scale catalyst loading and activity testing; (D) unloaded spent catalyst; (E) metal recovery process and; (F and $\mathrm{G}$ ) recovered alumina and metals from spent catalyst.

Considering the effectiveness in commercial applicability of these steps, the proposed processes will minimize spent catalyst waste generation. Utilization to

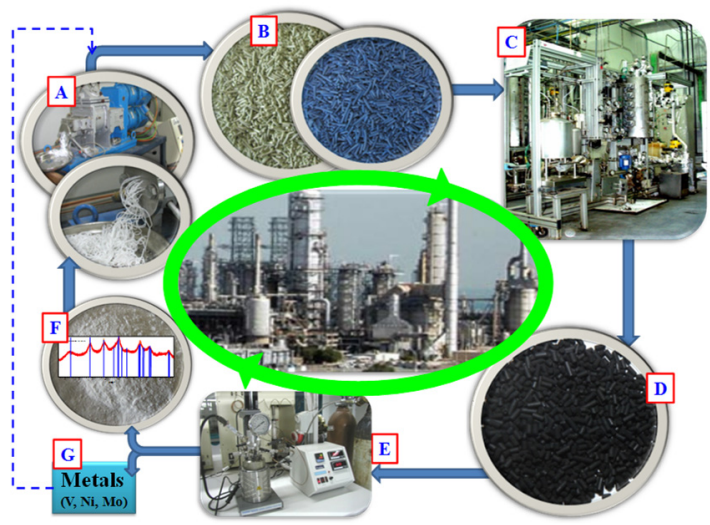

Figure 8: Residue hydroprocessing and its spent catalyst recycling steps. 
produce new catalysts and other useful materials, recycling through recovery of metals and support in order to achieve the safe disposal of spent catalysts.

\section{Conclusions}

The development of processes for the minimization and recycling of spent hydrotreating catalyst waste has received increasing attention in recent years due to the hazardous nature and stringent environmental regulations on its disposal. Based on the current study, due to the low process cost, high metal recovery and cleaner environment, hydrometallurgy will displace inefficient pyrometallurgy processes in coming years. The recovery process invariably involves a combination of pyro- and hydrometallurgical operations in order to have fully marketable products of metals and support. The total recycling process demonstrated its ability to reduce hazardous waste disposal to the zero limit and save natural resources with economic benefits. The recovered metals such as Mo. $\mathrm{V}, \mathrm{Ni}$ and Co could be used in steel manufacture and the alumina could be used for the manufacture of refractories, ceramics and abrasives. The total spent catalysts' recovery process is not only an economical process that recovers metals and support but is also a vital option for waste recycling and re-utilization.

\section{Acknowledgement}

The authors wish to thank the Kuwait Foundation for the Advancement of Science (KFAS) for their financial support (project: PF037C).

\section{References}

[1] Rana, M.S., Ancheyta, J., Sahoo, S.K., Rayo, P. Carbon and metal deposition during the hydroprocessing of Maya crude oil, Catal. Today 220222, 97-105, 2014.

[2] Marafi, M., Stanislaus, A., Furimsky, E., Handbook of Spent Hydroprocessing Catalysts: Regeneration, Rejuvenation, Reclamation, Environment and Safety, Elsevier, 2010.

[3] Global Hydroprocessing Catalyst (HPC) Market (2015): An Analysis, http://www.researchandmarkets.com/reports/1958130/

[4] World Refining Catalyst Market, The Catalyst Group Resources; The Intelligence Report, May 2014.

[5] Refining Report Catalyst handling, disposal become more important in environmental era, Oil \& Gas Journal (March 18) vol. 94(12), 1996.

[6] Trevino, C. New EPA rule will affect spent catalyst management, Oil \& Gas Journal, (Oct. 12, 1998) vol. 96(41), 1998.

[7] Ancheyta, J., Trejo, F., Rana, M.S. Asphaltenes: Chemical Transformation during Hydroprocessing of Heavy Oils, Taylor \& Francis Group, LLC, New York, 2009. 
[8] Rana, M.S., Samano, V., Ancheyta, J., Diaz, J.A.I., A review of recent advances on process technologies for upgrading of heavy oils and residua. Fuel, 86, 1216-1231, 2007.

[9] Furimsky, E., Massoth, F.E., Deactivation of hydroprocessing catalysts, Catal. Today, 52, 381-495, 1999.

[10] Sheeha, H., Marafi, M., Raghavan, V. Rana, M.S. Recycling and Recovery Routes for Spent Hydroprocessing Catalyst Waste, Ind. Eng. Chem. Res., 52(36), 12794-12801, 2013.

[11] Marafi, M., Al-Omani, S., Al-Sheeha, H., Stanislaus, A. Utilization of metal-fouled spent residue hydroprocessing catalyst in the preparation of an active HDM catalyst, Ind. Eng. Chem. Res. 46, 1968-1974, 2007.

[12] Marafi, M. \& Stanislaus, A., Options and processes for spent catalyst handling and utilization. J. Hazardous Materials, 101, 123-132, 2003.

[13] Marafi, M. \& Stanislaus, A. Spent catalyst waste management: A review: Part II-Advances in metal recovery and safe disposal method, Res., Cons. and Rec., 53, 1-26, 2008.

[14] Trimm, D.L. in: G. Ertl, H. Knozinger, J. Weitkamp (Eds.), Handbook of Heterogeneous Catalysts, vol. 3 Wiley-VCH, Weinheim p. 1263, 1997.

[15] Rostrup-Nielsen in, J. R., Bartholomew, C.H., Butt, J. B. (eds.): Catalyst Deactivation, Elsevier Science, Amsterdam 1991.

[16] Marafi, M., Stanislaus, A., Mumford, C.J. Studies on rejuvenation of spent residue hydroprocessing catalysts by leaching of foulant metals: influence of inorganic salt additive on the leaching efficiency of organic acids, Catal. Letter, 18, 141-151, 1993.

[17] Marafi, M. Process for recovering boehmite and $\gamma-\mathrm{Al}_{2} \mathrm{O}_{3}$ from spent hydroprocessing catalyst, US Patent Application 2012/0051988A1.

[18] Fauchais, P., Vardelle M. Plasma spraying: present and future. Pure Appl. Chem. 66,1247-1258, 1994.

[19] Marafi, M. \& Stanislaus, A., Studies on recycling and utilization of spent catalysts: Preparation of active HDM catalyst composition from spent residue hydroprocessing catalysts. Appl. Catal B: Env. 71, 199-206, 2007.

[20] Glasson, C., Geantet, C., Lacroix, M., Labruyere, F., Dufresne, P. Beneficial effect of carbon on HDT catalysts, J. Cat. 212, 76-85, 2002.

[21] Moreno-Castilla, C., Maldonado-Hodar, F.J. Carbon aerogels for catalysis applications: An overview, Carbon, 43, 455-465, 2005.

[22] Marafi, M. \& Stanislaus, A., Alumina from reprocessing of spent hydroprocessing catalyst. Catal. Today, 178, 117-123, 2011.

[23] Marafi, M., Rana, M.S. Refinery waste spent hydroprocessing catalyst: Leaching of metals using ammonium salts, Process Safety and Environmental Protection, submitted Oct., 2015, Under revision.

[24] Marafi, M. and Stanislaus, A., Waste catalyst utilization: extraction of valuable metals from spent hydroprocessing catalysts by ultrasonic-assisted leaching with acids. Ind. Eng. Chem. Res., 50, 9495-9501, 2011. 